\title{
Constitutive activity of NF-kappa B in myeloid cells drives pathogenicity of monocytes and macrophages during autoimmune neuroinflammation
}

\author{
Gisa Ellrichmann ${ }^{1}$, Jan Thöne ${ }^{1}$, De-Hyung Lee ${ }^{1,3}$, Rudolph A Rupec ${ }^{2}$, Ralf Gold ${ }^{1}$ and Ralf A Linker ${ }^{1,3^{*}}$
}

\begin{abstract}
The NF- $\kappa \mathrm{B} / \mathrm{REL}$-family of transcription factors plays a central role in coordinating the expression of a wide variety of genes controlling immune responses including autoimmunity of the central nervous system (CNS). The inactive form of $\mathrm{NF}-\kappa \mathrm{B}$ consists of a heterodimer which is complexed with its inhibitor, $\mid \kappa \mathrm{B}$. Conditional knockout-mice for $\mid \kappa \mathrm{B} \alpha$ in myeloid cells (lys $\mathrm{MCrel} \kappa \mathrm{B} \alpha^{\mathrm{fl} / \mathrm{fl}}$ ) have been generated and are characterized by a constitutive activation of $\mathrm{NF}-\kappa \mathrm{B}$ proteins allowing the study of this transcription factor in myelin-oligodendrocyte-glycoprotein induced experimental autoimmune encephalomyelitis (MOG-EAE), a well established experimental model for autoimmune demyelination of the CNS.

In comparison to controls, lys $\mathrm{MCrel} \kappa \mathrm{Ba}^{\mathrm{fl} / \mathrm{fl}}$ mice developed a more severe clinical course of EAE. Upon histological analysis on day 15 p.i., there was an over two fold increased infiltration of T-cells and macrophages/microglia. In addition, lys $\mathrm{MCrel} \kappa \mathrm{B} \alpha^{\mathrm{f} / \mathrm{fl}}$ mice displayed an increased expression of the NF- $\kappa \mathrm{B}$ dependent factor inducible nitric oxide synthase in inflamed lesions. These changes in the CNS are associated with increased numbers of CD11b positive splenocytes and a higher expression of Ly6c on monocytes in the periphery. Well in accordance with these changes in the myeloid cell compartment, there was an increased production of the monocyte cytokines interleukin(IL)-12 p70, IL-6 and IL-1 beta in splenocytes. In contrast, production of the T-cell associated cytokines interferon gamma (IFN-gamma) and IL-17 was not influenced.

In summary, myeloid cell derived NF- $\kappa$ B plays a crucial role in autoimmune inflammation of the CNS and drives a pathogenic role of monocytes and macrophages independently from T-cells.
\end{abstract}

Keywords: NF-kappaB, myeloid cells, cytokines, experimental autoimmune encephalomyelitis

\section{Background}

Multiple sclerosis (MS) is the most common human demyelinating disease of the central nervous system (CNS). The development of autoimmune diseases such as MS requires the coordinated expression of a number of pro-inflammatory genes. These factors may influence the activation, migration and effector function of inflammatory cells and encompass a variety of cytokines, chemokines, adhesion molecules as well as other inflammatory factors.

\footnotetext{
* Correspondence: Ralf.Linker@uk-erlangen.de

'Department of Neurology, St. Josef Hospital Bochum, Ruhr-University Bochum, Germany

Full list of author information is available at the end of the article
}

Nuclear factor (NF-) kappaB (NF- $\kappa \mathrm{B})$ is essential for both innate and adaptive immunity [1]. NF- $\kappa \mathrm{B}$ is an inducible transcription factor which is detected in most cell types and is involved in many inflammatory processes. It consists of homo- or heterodimers of different subunits and structurally related proteins (Rel/NF- $\kappa \mathrm{B}-$ proteins). There are at least five Rel/NF- $\kappa \mathrm{B}$ proteins: c-Rel, RelA (p65), RelB, NF- $\kappa$ B1 (p50/p105), NF- $\kappa$ B 2 (p52/p100) [1-4]. The transcriptional activation of the NF- $\kappa \mathrm{B}$ pathway is controlled by the inhibitor of NF- $\kappa \mathrm{B}$, $\mathrm{I} \kappa \mathrm{B}$. $\mathrm{I} \kappa \mathrm{B}$ is phosphorylated by $\mathrm{I} \kappa \mathrm{B}$ kinase (IKK), a complex that is composed of a regulatory subunit IKK- $\gamma$. Polyubiquitinylation of $\mathrm{I} \kappa \mathrm{B}$ induces NF- $\kappa \mathrm{B}$ dimers to

\section{C) Biomed Central}


translocate to the nucleus, inducing the transcription of over 150 target genes [5].

Besides the involvement of NF- $\kappa \mathrm{B}$ in T-cell proliferation and activation [6-8], it is also a key element in coordinately controlling gene expression during monocyte/ macrophage activation [9]. In particular the macrophagederived cytokines interleukin-1beta (IL-1 $\beta$ ) and tumor necrosis factor-alpha (TNF- $\alpha$ ), are potent activators of $\mathrm{NF}-\kappa \mathrm{B}$. In turn, their expression is controlled by NF- $\kappa \mathrm{B}$ thus resulting in a positive feedback loop. Hence, NF- $\kappa$ B signalling pathways may play a pivotal role in activating myeloid cell function during autoimmune inflammation. In addition to its central mediatory function in cytokine expression, NF- $\kappa \mathrm{B}$ in myeloid cells may be induced by physical as well as oxidative stress to cells, e.g. via the inducible nitric oxide synthase (iNOS) [10] or cyclooxygenase-2 (COX-2) [11].

In our study, we investigated the role of NF- $\kappa \mathrm{B}$ in myeloid cells during autoimmune demyelination of the CNS. For the targeted analysis of NF- $\kappa \mathrm{B}$ functions in monocytes/macrophages, conditional knockout-mice for $\mathrm{I} \kappa \mathrm{B} \alpha$ in myeloid cells (lysMCreI $\kappa \mathrm{Ba}{ }^{\mathrm{fl} / \mathrm{fl}}$ mice) have been generated [12]. These mice display a constitutive expression of NF- $\kappa \mathrm{B}$ proteins in macrophages and monocytes, but no spontaneous myelopoetic phenotype thus allowing for studying the role of this transcription factor in myelin-oligodendrocyte-glycoprotein induced experimental autoimmune encephalomyelitis (MOG-EAE). Our results demonstrate that NF- $\kappa \mathrm{B}$-dependent pro-inflammatory gene expression in monocytes and macrophages plays an important role for CNS pathology in autoimmune neuroinflammation. In turn, targeting the IKK-NF- $\kappa \mathrm{B}$ pathway in myeloid cells might constitute an interesting therapeutic target in MS.

\section{Methods}

\section{Animals}

Conditional knockout-mice for $\mathrm{I} \kappa \mathrm{B} \alpha$ in myeloid cells (lysMCreI $\kappa \mathrm{Ba}^{\mathrm{fl} / \mathrm{fl}}$ mice) have been generated at the Ludwigs-Maximilians-University, Munich, Germany [12] and were backcrossed to the C57BL/6 background for more than 10 generations. Complete inactivation of $\mathrm{I} \kappa \mathrm{B} \alpha$ results in hypergranulopoiesis and perinatal death. Therefore the Cre-loxP recombination system was used to generate a mouse line that allows for selective deletion of $\mathrm{I} \kappa \mathrm{B} \alpha$. The targeting construct was designed in a way that Cre-mediated recombination results in deletion of the promoter region containing essential regulatory NF$\kappa \mathrm{B}$ binding sites. These conditional $\mathrm{I} \kappa \mathrm{B}$ knockout mice displayed constitutively high nuclear levels of NF- $\kappa \mathrm{B}$ in myeloid cells. C57BL/6 mice for backcrossing and controls were bred in the same mouse colony. All mice were housed under pathogen free conditions at the animal facility of the Ruhr-University Bochum, Germany. All experiments have been reviewed and approved by the North-Rhine-Westphalia authorities for animal experimentation. Mice were given food and water at libidum and were weighed daily to obtain weight curves. All animal experiments were approved by the local authorities for animal experimentation (approval ID: $50.8735 .1 \mathrm{Nr}$. $114 / 6, \mathbb{8} 8$ Protection of Animals Act). For survival analysis, cohorts of mice were followed over the course of disease with moribund mice sacrificed according to animal protection laws.

\section{Induction of EAE}

Ten-week-old C57BL/6 female mice and lysMCreI $\kappa \mathrm{Ba}^{\mathrm{fl} / \mathrm{fl}}$ knockout mice were immunized via subcutaneous injection of $200 \mu \mathrm{g} \mathrm{MOG}_{35-55}$ peptide (Charité, Berlin, Germany) in complete Freund's adjuvant containing $200 \mu \mathrm{g}$ Mycobacteria tuberculosis (Difco/BD Biosciences, Heidelberg, Germany). All mice received 200 ng pertussis toxin (List/Quadratec, UK) on days 0 and 2 post immunization by intraperitoneal injection.

Mice were weighed and scored for clinical signs daily according to a 10-scale score as described previously [13].

\section{Splenocyte culture and proliferation assay}

For cytokine assays, splenocytes were cultured at $6 \times 10^{6}$ cells/well in 24 well plates containing $1 \mathrm{ml}$ in RPMI medium/well (Gibco, Eggenstein, Germany) with various concentrations of $\mathrm{MOG}_{35-55}$ peptide, or ConA $(1.25 \mu \mathrm{g} / \mathrm{ml})$. For the criss-cross proliferation assay, a MACS ${ }^{\mathbb{B}}$ cell separation (Pan-T-cell kit, Milentyi) for T-cells was used. Both pooled APC and T-cells were isolated form MOGimmunized mice on day 10 after immunization. Culture supernatants for cytokine analysis were collected $48 \mathrm{~h}$ later. For proliferation assays, $0.3 \times 10^{6}$ cells/well were used in 96 well plates. $\left[{ }^{3} \mathrm{H}\right]$ thymidine was added to each culture at $48 \mathrm{~h}$ and cells were harvested $16 \mathrm{~h}$ later. Data are depicted as stimulatory index indicating the fold increase in $\left[{ }^{3} \mathrm{H}\right]$ thymidine incorporation as compared to medium only.

\section{Histological analyses}

Mice were deeply anesthetized with ketamine and transcardially perfused with $4 \%$ paraformaldehyde in phosphate buffered saline (PBS, pH 7.4) for light microscopy and immunohistochemistry.

Spinal cord was removed, embedded in paraffin and routinely processed to obtain 12 cross sections per mouse. Routine stainings comprised cresyl violet staining, Luxol Fast Blue for myelin and Bielschowsky silver impregnation for axons. Immunohistochemistry including iNOS staining (1:200; Millipore, Schwalbach, Germany) was performed on $3 \mu \mathrm{m}$ thick paraffin sections. All other histological procedures were essentially performed as described previously 
[13]. Briefly, T-cells were labeled by rat anti-CD3 (Serotec; Wiesbaden, Germany; 1: 300), macrophages/microglia by rat anti-mouse Mac-3 (BD Heidelberg, Germany; 1:200) and neutrophils by rat anti 7/4 antigen (Serotec; 1:300).

\section{Assay of cytokines by ELISA}

Cell culture supernatants were collected, aliquoted and stored at $-20^{\circ} \mathrm{C}$. Immediately before measurement, aliquots were brought to room temperature and analyzed for Interleukin (IL) IL-1 $\beta$, IL-6, IL-12(p40), IL-12(p70), IL-17 and interferon gamma (IFN- $\gamma$ ) using sandwich ELISA kits (BD and R\&D Systems, Minneapolis, USA) according to manufacturers' protocols.

\section{CD11b cell isolation and FACS analysis}

Splenic CD11b+ cells were isolated by magnetic cell sorting (MACS) according to manufacturer's protocols (Miltenyi Biotec, Auburn, USA). The purification level of CD11b + exceed routinely 95\%. The expression of CD11b, CD80, CD86, MHC class II (MHC-II) and Ly6c was evaluated both prior and subsequent to MACS using a FACS Canto II and CellQuest software (BD, Heidelberg, Germany). Monoclonal antibodies were all purchased from BD.

\section{Quantification and statistical analyses}

All neuropathological and scoring analyses were performed completely blinded. All data are presented as mean \pm SEM. Histological quantification was performed by means of overlaying a stereological grid onto the sections and counting T-cells, macrophages/microglia, neutrophils, iNOS positive profiles and axonal densities on 6 lesions per mouse from representative spinal cord cross sections comprising cervical, thoracic and lumbar spinal cord as described previously [13]. Axonal densities were counted using a 24 point eyepiece from Olympus (Hamburg, Germany), and the number of points crossing axons was measured as a fraction of the total number of points on the sterological grid [14]. Demyelination was analyzed semi-automatically with the CellD software (Olympus).

Statistical analysis was performed by Mann-Whitney Utest for histological evaluations and clinical course, by ttest, for ELISA and FACS analyses and by two-way ANOVA with Dunn's post test for proliferation assays (all analyses done by Graph Pad Prism 5, San Diego, CA, USA). In all experiments, a probability level of * $\mathrm{p}<0.05$, *** $\mathrm{p}<0.01,{ }^{* * * *} \mathrm{p}<0.001$ was considered to be statistically significant.

\section{Results}

Characterization of mice with a conditonal $\mathrm{I} \kappa \mathrm{B}$ deletion in myeloid cells

In this study, we employ lysMCreI $\kappa \mathrm{B} \alpha^{\mathrm{fl} / \mathrm{fl}}$ mice to analyze the role of NF- $\kappa \mathrm{B}$ in monocytes during autoimmune inflammation. While these mice have been characterized in detail before [12], we analyzed the expression of the active, phosphorylated p65 NF- $\kappa \mathrm{B}$ subunit in naive monocytes by confocal laser scanning microscopy (Figure 1). To this end, CD11b-positive monocytes from lysMCreI $\kappa \mathrm{B}^{\mathrm{fl} / \mathrm{fl}}$ or wild-type control mice were isolated and used for anti-NF- $\kappa \mathrm{B}-\mathrm{p} 65$ immunocytochemistry. Double label experiments with TOTO-3 as nuclear staining revealed that naive monocytes from lysMCreI $\kappa \mathrm{Ba}^{\mathrm{fl} / \mathrm{fl}}$ mice showed constitutive activity of p65 in monocytes while there was no NF- $\kappa \mathrm{B}$ activation in naive monocytes from wild-type controls. In summary, naive monocytes from lysMCreI $\kappa \mathrm{Ba}^{\mathrm{fl} / \mathrm{fl}}$ mice are characterized by an increased activity of the NF- $\kappa \mathrm{B}$ system and constitute a useful tool to study the role of NF- $\kappa \mathrm{B}$ in monocytes during autoimmune inflammation.

We next investigated the functional impact of the conditonal $\mathrm{I} \kappa \mathrm{B}$ deletion in naive $\mathrm{CD} 11 \mathrm{~b}$ positive splenocytes and in particular CD11b/Ly6c positive monocytes via FACS (Figure 2A, B). We observed a significantly higher number of spleen-derived CD11b positive cells and a higher total cell count of CD11b/Ly6c double positive cells in spleens from lysMCreI $\kappa \mathrm{B} \alpha^{\mathrm{fl} / f l}$ mice (Figure $2 \mathrm{~B}$, Table 1 ). FACS analyses of CD11 positive cells after MACS sorting did not reveal any significant differences in the expression of CD80, CD86 and MHC-II (Figure 2C). However, expression of Ly6c was significantly increased on CD11b cells from lysMCreI $\kappa \mathrm{Ba}^{\mathrm{fl} / \mathrm{fl}}$ mice (Figure 2D).

\section{Constitutive activation of NF- $\kappa$ B in myeloid cells leads to a more severe course of MOG-EAE with enhanced inflammatory infiltration and demyelination}

To investigate the role of a constitutive activation of NF$\kappa \mathrm{B}$ in myleoid cells during autoimmune neuroinflammation, we analyzed clinical symptoms and disease severity of MOG-EAE in lysMCreI $\kappa \mathrm{B} \alpha^{\mathrm{fl} / \mathrm{fl}}$ mice as compared to age and gender matched wild-type control mice (Figure 3 ). Disease incidence and mortality from EAE did not differ between groups (wild-type mice $\mathrm{n}=13$ and lysM$\mathrm{CreI} \kappa \mathrm{B} \alpha^{\mathrm{fl} / \mathrm{fl}}$ mice $\left.\mathrm{n}=14\right)$. However, lysMCreI $\kappa \mathrm{B} \alpha^{\mathrm{fl} / \mathrm{fl}}$ mice displayed a significantly more severe clinical course of EAE. On day 20 post immunization, conditional knockout mice suffered from severe paraparesis while mice in the control group only displayed severe gait ataxia.

Next, we focused on histological analyses to determine whether the clinical differences between groups correlated with enhanced infiltration of inflammatory cell subsets in the CNS as well as demyelination and axonal damage. Upon histological analysis of spinal cord cross sections on day 15 post immunization, there was an increased number of inflammatory infiltrates and an increased infiltration of CD3 positive T-cells as well as Mac-3 macrophages/microglia and an increased amount of iNOS positive cells in lysMCreI $\kappa \mathrm{Ba}^{\mathrm{fl} / \mathrm{fl}}$ mice (Table 2 and Figure 4). The analysis of myelin loss after Luxol Fast 

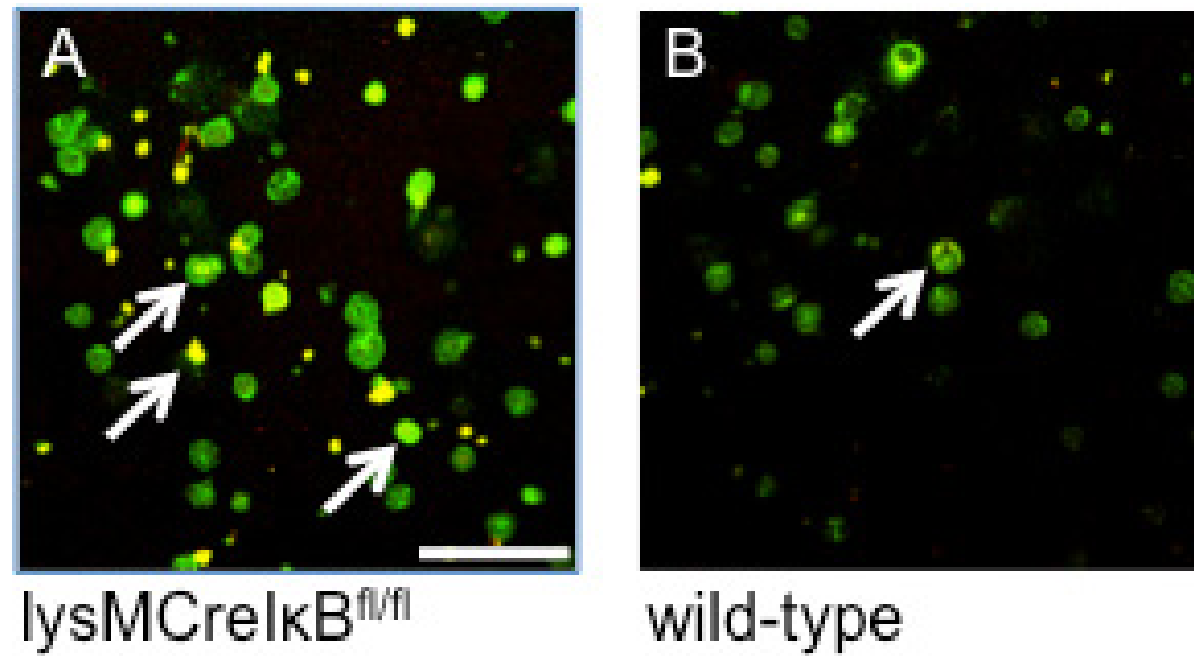

Figure 1 Constitutive activation of $\mathbf{N F}-\kappa \mathbf{B}$ in lysMCrel $\kappa \mathbf{B} \alpha^{\mathrm{fl} / \mathrm{fl}}$ monocytes. Representative cytospins of naïve CD $11 \mathrm{~b}$-sorted spleen monocytes from lysMCrel $\kappa \mathrm{B} \alpha^{\mathrm{fl} / \mathrm{fl}}$ mice (A) or wild-type controls (B) after staining for the NF- $\kappa \mathrm{B}$ p65 subunit and nuclear co-staining with TOTO-3. Note the accumulation of active NF- $\kappa$ B in the nucleus of monocytes from a representative lys MCrel $\kappa B \alpha^{\mathrm{fl} / f \mathrm{l}}$ mouse (marked by arrows). Bar $=20 \mu \mathrm{m}$.

Blue staining showed a significant increase in demyelination in lysMCreI $\kappa \mathrm{Ba}^{\mathrm{fl} / \mathrm{fl}}$ mice (Figure 4). Upon evaluation of axonal densities after Bielschowsky silver impregnation as well as numbers of iNOS positive cells and infiltrating 7/4-antigen positive neutrophils, there was a trend towards enhanced axonal injury as well as an increased neutrophil infiltration in lysMCreI $\kappa \mathrm{Ba}^{\mathrm{fl} / \mathrm{fl}}$ mice, but without statistical significance (Table 2).

We also examined inflammatory infiltration at a later time point (day 30 p.i.) which revealed less inflammation, but a similar trend towards enhanced inflammatory infiltration in lysMCreI $\kappa \mathrm{Ba}^{\mathrm{fl} / \mathrm{fl}}$ mice (data not shown).

Constitutive activation of NF- $\kappa$ B in myeloid cells results in increased monocyte cytokine production

Since we found a more severe EAE with enhanced inflammatory infiltration in lysMCreI $\kappa \mathrm{B}^{\mathrm{fl} / \mathrm{fl}}$ mice, we next examined the involved immunological processes in this model. To this end, we analyzed T-cell proliferation and cytokine production in splenocyte primary cultures from MOG-immunized mice after recall with MOG antigen. In co-culture experiments of wild-type T-cells with lysM$\mathrm{CreI} \kappa \mathrm{B} \alpha^{\mathrm{fl} / \mathrm{fl}}$ antigen presenting cells and vice versa, we found an increased $\mathrm{T}$-cell proliferation specifically after culture of lysMCreI $\kappa \mathrm{B}^{\mathrm{fl} / \mathrm{fl}} \mathrm{T}$-cells with lysMCreI $\kappa \mathrm{B}^{\mathrm{fl} / \mathrm{fl}}$ APC and after stimulation with ConA (Figure 5). Upon analysis of IL-1 $\beta$, IL-6, and IL-12(p40/70) after re-stimulation with MOG in splenocyte culture (Figure 6A-D), there was a significant increase of the NF- $\kappa \mathrm{B}$ dependent monocyte cytokines IL-1 $\beta$, IL- 6 and IL12p70 in the supernatant from lysMCreI $\kappa \mathrm{Ba}^{\text {fl/fl }}$ mice as compared to controls (Figure 6B-D). In contrast, production of the T-cell cytokines IL-17 and IFN- $\gamma$ was not influenced (Figures 6E, F).
In summary, lysMCreI $\kappa \mathrm{B} \alpha^{\mathrm{fl} / \mathrm{fl}}$ mice displayed an altered monocyte cytokine profile which was associated with an increased production of IL-1 $\beta$, IL-6, and IL-12 (p70) in splenocyte culture.

\section{Discussion}

Here we analyze the role of monocyte/macrophage derived $\mathrm{NF}-\kappa \mathrm{B}$ in autoimmune demyelination. We studied EAE in mice which are devoid of $\mathrm{I} \kappa \mathrm{B} \alpha$ in myeloid cells (lysM$\mathrm{CreI} \kappa \mathrm{B} \alpha^{\mathrm{fl} / \mathrm{fl}}$ mice). In these mice, loss of $\mathrm{I} \kappa \mathrm{B}$ in monocytes and macrophages leads to constitutive expression of NF$\kappa \mathrm{B}$. In turn, this results in an increased expression of NF$\kappa \mathrm{B}$ regulated monocyte/macrophage cytokines and subsequently enhanced macrophage infiltration and iNOS expression in the spinal cord of EAE mice. These mechanims govern demyelination, enhanced axonal damage and finally a more severe course of MOG-EAE. Thus macrophage derived, NF- $\kappa$ B dependent cytokines may play a pivotal role in the pathogenesis of EAE and determine the outcome of autoimmune inflammation in the CNS without interfering with Th1 and Th17 T-cell responses. Our findings suggest that NF- $\kappa \mathrm{B}$ in myeloid cells is a master regulator for regulation of inflammation and tissue damage in autoimmune inflammation of the CNS.

Previous studies already investigated the role of NF- $\kappa \mathrm{B}$ in the CNS [15], in autoimmune diseases [16] and also during EAE. The analysis of $\mathrm{c}$-Rel or NF- $\kappa \mathrm{B} 1$-deficient mice as well as IKK-2-deficient mice revealed that NF- $\kappa \mathrm{B}$ activation in T-cells significantly contributes to the initiation of autoimmune neuroinflammation $[17,18]$. Myelinspecific T-cells in NF- $\kappa \mathrm{B} 1$ (p50)-deficient mice are deficient in differentiating into either Th1 or Th2 cells [17]. This concept was further refined by Dasgupta and co- 


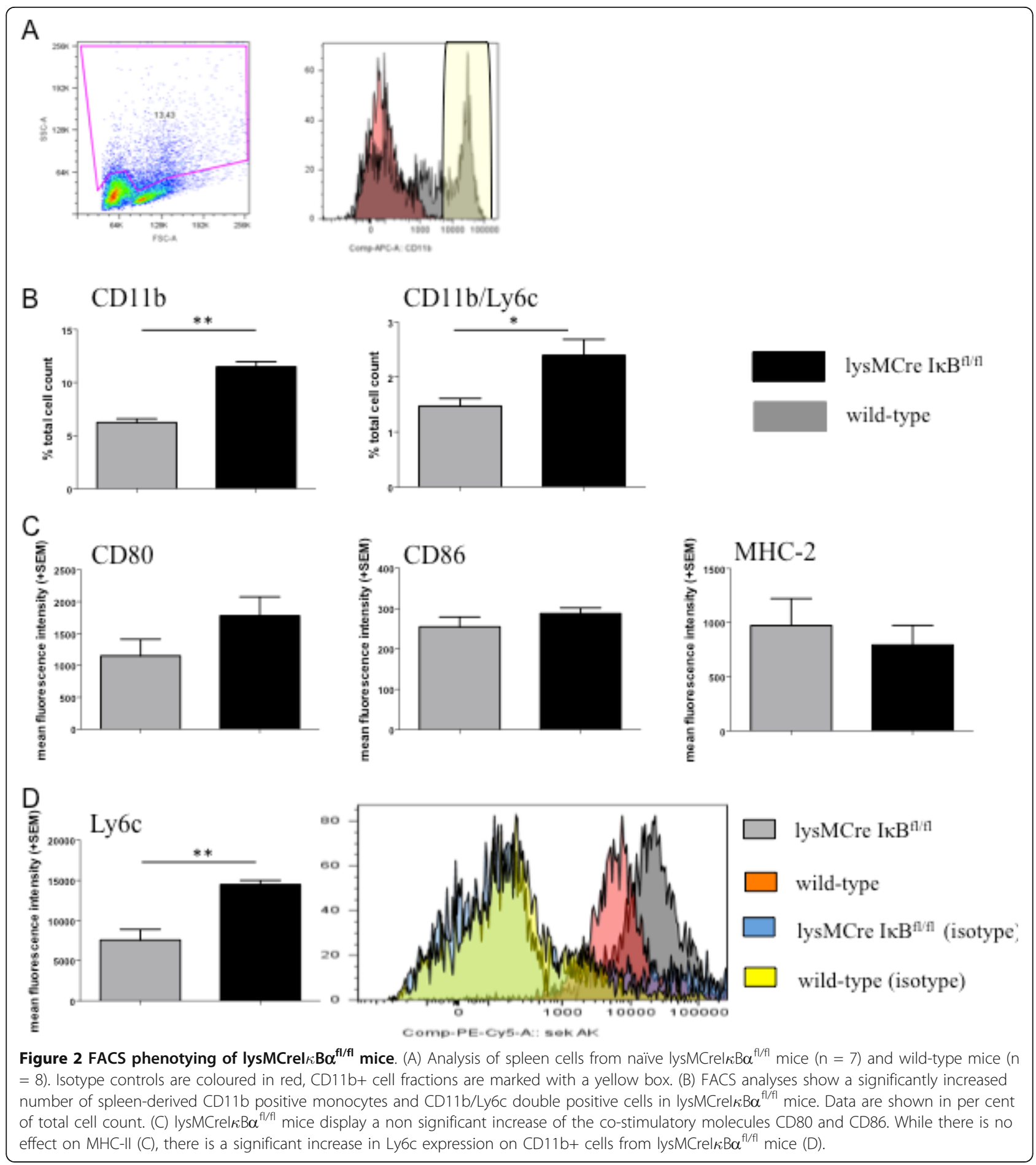

Table 1 FACS analyses

\begin{tabular}{lllll}
\hline & lysMCrel $\kappa$ B $\boldsymbol{\alpha}^{\text {fl/fl }}$ & wild-type & $\boldsymbol{p}$-value & $\mathbf{n}$ \\
\hline \% of CD11b positive spleen cells $[ \pm$ SEM] & $11.5 \pm 1.3$ & $6.2 \pm 1.0$ & 0.0003 & $7 / 8$ \\
absolute numbers of CD11b positive spleen cells [ \pm SEM] & $2299.7 \pm 98$ & $1246 \pm 69$ & 0.0003 & $7 / 8$ \\
\hline
\end{tabular}

Quantification of CD11b positive spleen cells. 20.000 cells/mouse were analyzed. 


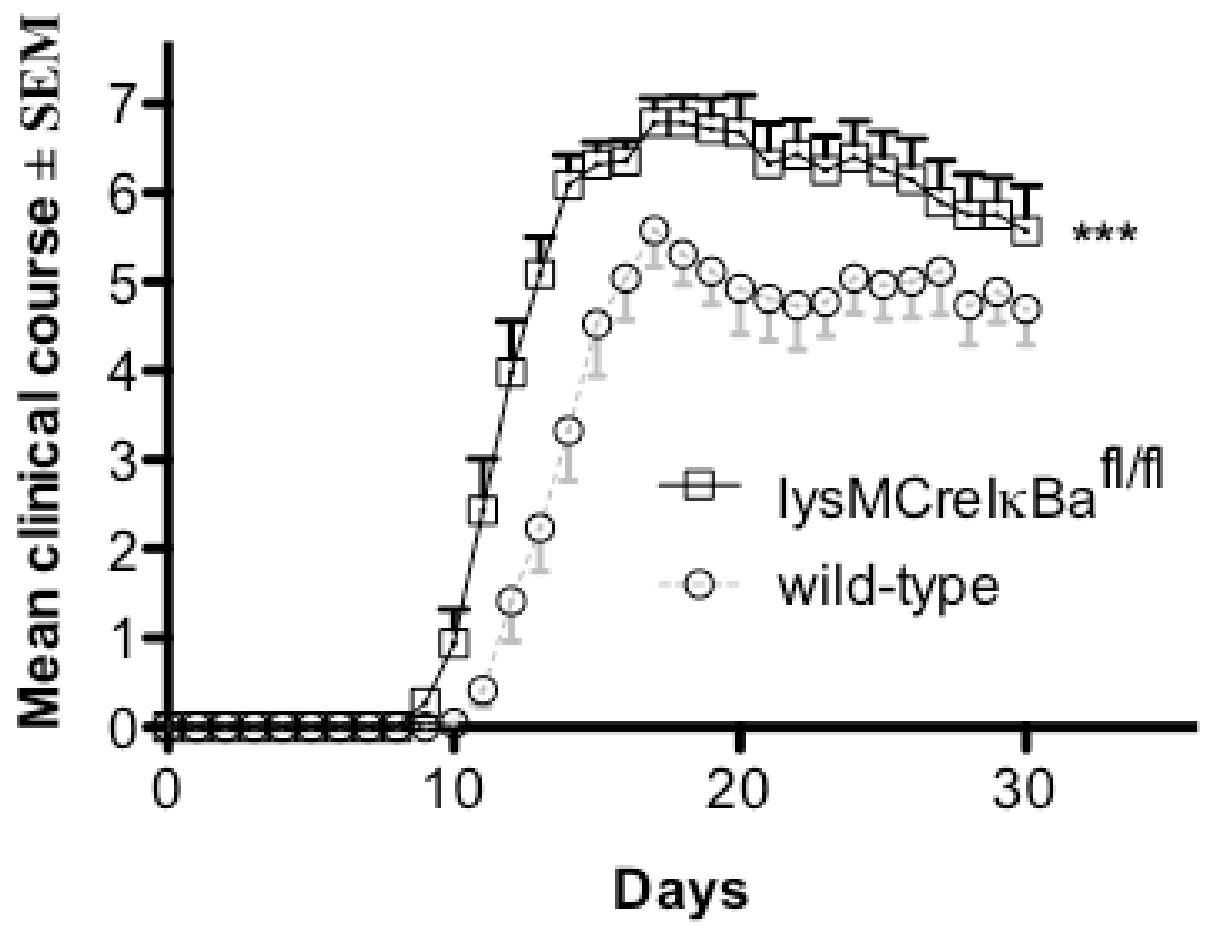

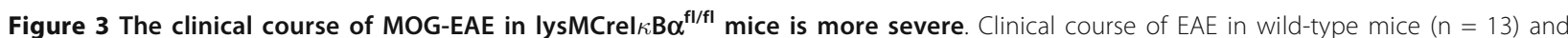
lys $\mathrm{MCrel} \kappa \mathrm{B \alpha}^{\mathrm{fl} / f l}$ mice $(\mathrm{n}=14)$. lysMCrel $\kappa \mathrm{B} \alpha^{\mathrm{fl} / \mathrm{fl}}$ mice (black curve) show a significantly earlier start and a more severe course of disease compared to wild-type mice (grey curve). Data represent the mean of two independent experiments \pm SEM.

workers who showed positive effects of NF- $\kappa \mathrm{B}$ on the differentiation of myelin-specific Th1 cells, but a negative influence on the differentiation into Th2 cells [19]. In line with these observations, severely impaired T-cell responses were found in immune cell cultures derived from mice with a $\mathrm{T}$-cell specific deficiency in IKK2, a pivotal kinase for NF- $\kappa$ B activation (IKK2 ${ }^{\Delta \text { T-cell }}$ mice) [20].

Moreover, NF- $\kappa$ B may also play a role in the CNS cells during autoimmune demyelination. While studies by Wooten or Mattson and co-wokers in cell culture argue for a protective role of NF- $\kappa \mathrm{B}$ in neuronal cells $[21,22]$, our work with conditional overexpression of
NF- $\kappa \mathrm{B}$ in myeloid cells reveal monocytes/macrophages as a further cell type with crucial importance of NF- $\kappa \mathrm{B}$ in neuroinflammation.

Many studies have demonstrated a critical role for macrophages/microglia as well as an up-regulation of MHC class II in these cells in EAE and MS lesions $[23,24]$. Depletion experiments with liposomal dichloromethylene diphosphonate $\left(\mathrm{Cl}_{2} \mathrm{MDP}\right)$ revealed a crucial role of bone marrow derived macrophages for tissue damage in EAE [25,26]. Interestingly, histological analyses in these studies could not detect differences in number and localization of CNS infiltrating T-cells between $\mathrm{Cl}_{2} \mathrm{MDP}$ treated rats and controls [25]. These

Table 2 Histological analyses

\begin{tabular}{|c|c|c|c|c|}
\hline & lysMCrel $\kappa B \alpha^{f \mid / f l}$ & wild-type & $p$-value & $\mathrm{n}$ \\
\hline Inflammatory Index $[ \pm$ SEM $]$ & $16.0 \pm 1.9$ & $6.8 \pm 1.0$ & 0.0003 & $5 / 5$ \\
\hline CD $3\left[\right.$ cells $\left./ \mathrm{mm}^{2} \pm \mathrm{SEM}\right]$ & $251 \pm 19$ & $102 \pm 13$ & $<0.0001$ & $5 / 5$ \\
\hline Mac-3 $[ \pm$ SEM $]$ & $1123 \pm 81$ & $581 \pm 100$ & $<0.0001$ & $5 / 5$ \\
\hline iNOS $[ \pm$ SEM] & $333 \pm 75$ & $153 \pm 19$ & 0.0184 & $5 / 5$ \\
\hline$\%$ Demyelination $[ \pm$ SEM] & $8 \pm 0.8$ & $2 \pm 0.6$ & $<0.0001$ & $5 / 5$ \\
\hline Neutrophils $[ \pm$ SEM] & $339 \pm 37$ & $190 \pm 25$ & n.s & $5 / 5$ \\
\hline Axonal densities $[ \pm S E M]$ & $3.7 \pm 0.5$ & $2.9 \pm 0.3$ & n.s & $5 / 5$ \\
\hline
\end{tabular}

Blinded quantification of the inflammatory index after HE-staining, CD3 positive cells, Mac-3 positive macrophages/microglia, iNOS positive cells, demyelination after Luxol Fast Blue staining and axonal densities after silver impregnation were performed on day 15 p.i. marking the acute phase of the disease. Data are presented as cells $/ \mathrm{mm}^{2}$ for CD3, Mac-3, iNOS positive cells, percent demyelination for Luxol Fast Blue and relative axonal densities for silver impregnated axons. n.s = not significant. 


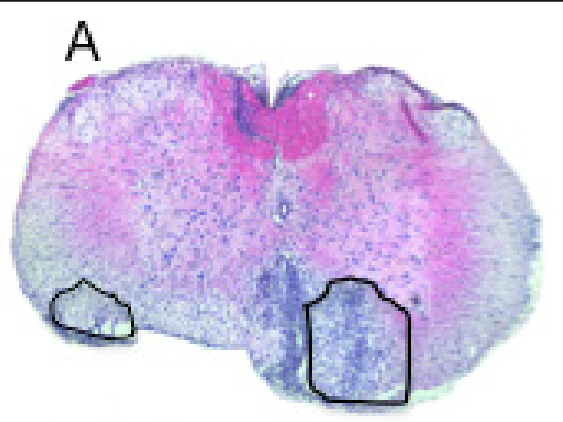

C

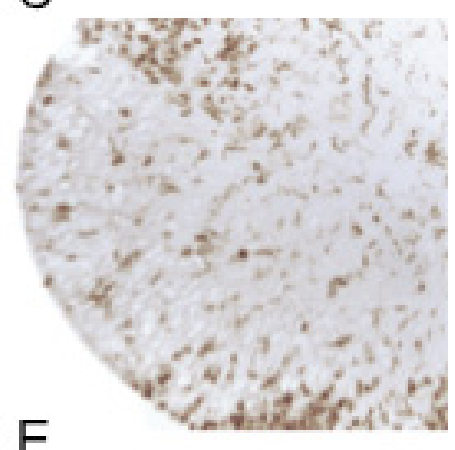

$\mathrm{E}$
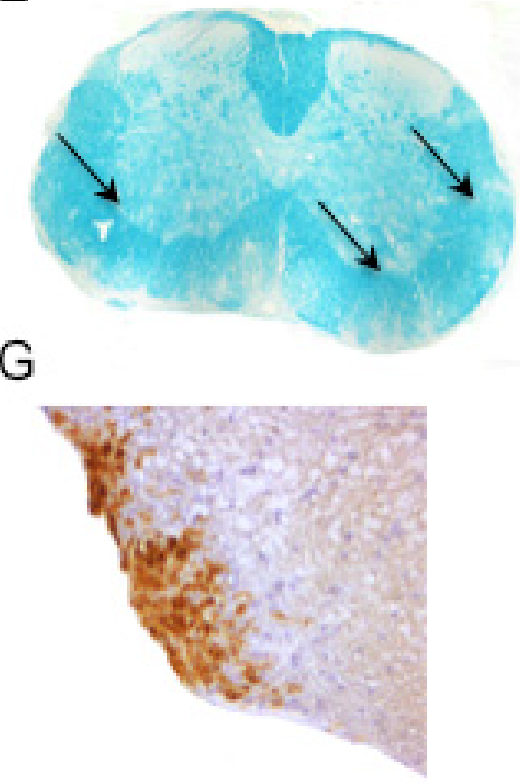

lysMCrelkBa $\mathrm{a}^{\mathrm{f} / \mathrm{fl}}$

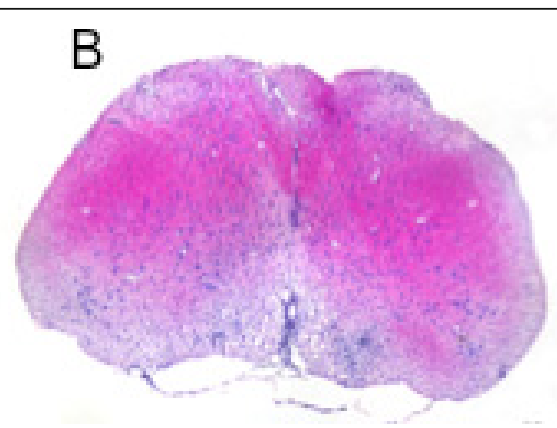

D
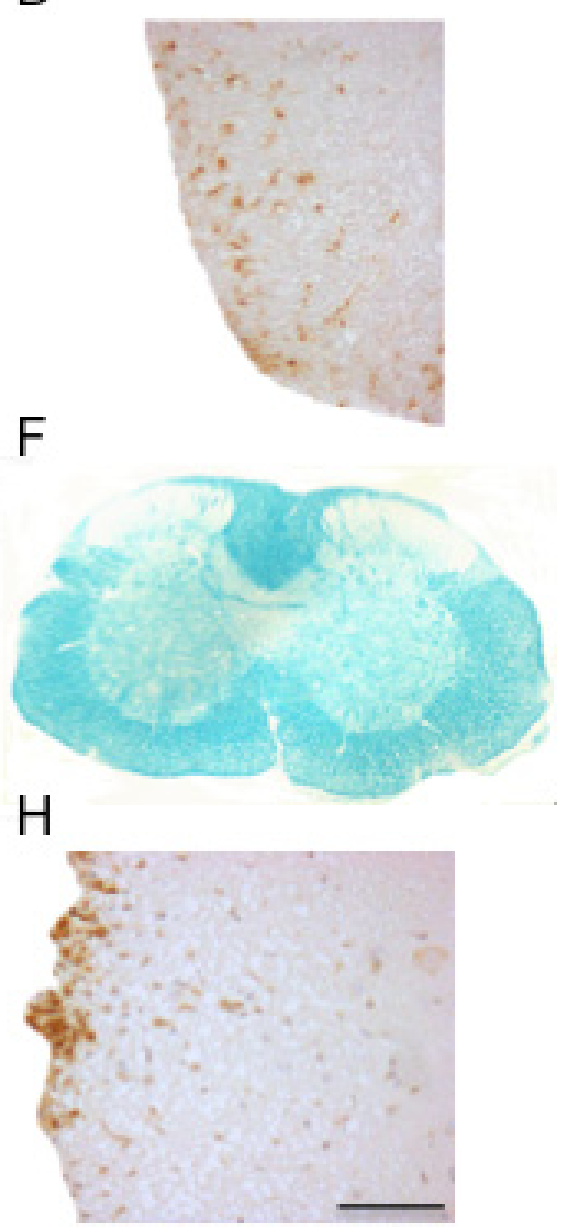

wild type

Figure 4 Enhanced inflammatory infiltration, demyelination and iNOS expression in lysMCrel $\kappa \mathbf{B \alpha}^{\mathrm{fl} / \mathrm{fl}}$ mice. Histological analyses of lysMCrel $\kappa B \alpha^{f / f l}$ mice $(A, C, E, G)$ versus wild-type mice $(B, D, F, H)$ result in increased inflammatory infiltration after HE staining or Mac-3 staining $(A, B, C, D)$ and increased demyelination after Luxol Fast Blue staining $(E, F)$. As compared to wild-type controls, lysMCrel $\kappa B^{\mathrm{fl} / f l}$ mice are also characterized by an increase in iNOS expression cells $(G, H)$. Representative images of spinal cord cross section in the acute phase on day 15 post immunization are shown. Infiltrated areas are marked in the knockout-mice group (A). Scale bar is only depicted in (H) for clarity and represents $200 \mu \mathrm{m}$ for $A, B, E, F$ and $20 \mu m$ in C, D, G, H.

data argue for a myeloid cell independent T-cell activation in EAE. Well in line with this concept, we did not observe any change in T-cell cytokine expression in our model. Indeed, not monocytes/macrophages, but rather dendritic cells as professional antigen presenting cells do play the major role for T-cell activation in EAE [27]. Furthermore, lysMCre mediated $\mathrm{I} \kappa \mathrm{B} \alpha$ deletion in our model does not involve dendritic cells and does not lead 


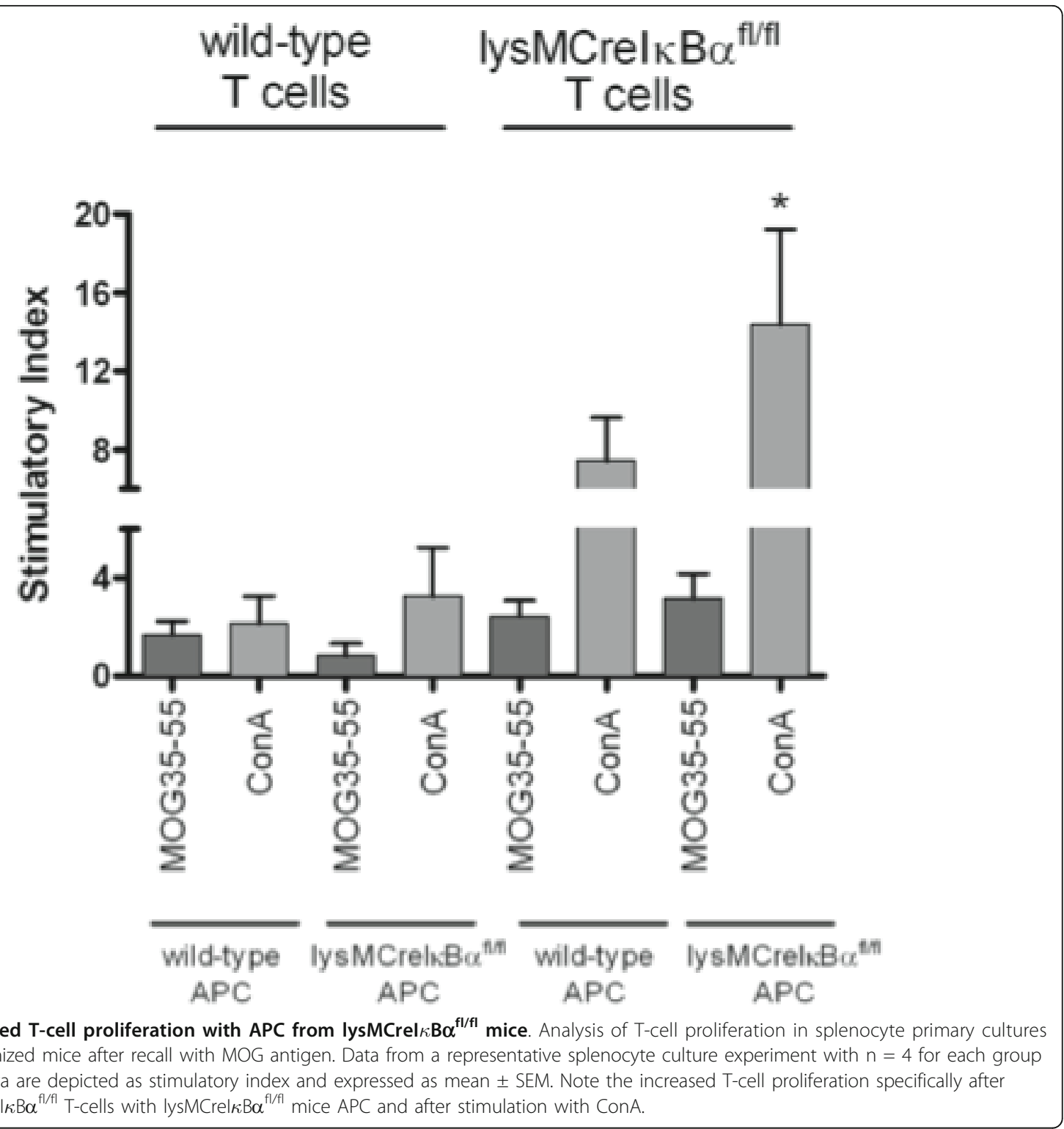

to effects on T-cell cytokines. Thus at first glance, NF- $\kappa \mathrm{B}$ in macrophages/monocytes may be more important for effector functions than for T-cell activation. Yet, changes in phagocyte cytokine patterns may eventually result in an enhanced T-cell activation over time which is not reflected in our analysis at day 10 after immunization. Further studies are warranted to dissect indirect effects of myeloid cell derived NF- $\kappa \mathrm{B}$ on T-cell function in the setting of chronic inflammation.

Our data reveal a crucial role of myeloid cell derived $\mathrm{NF}-\kappa \mathrm{B}$ for demyelination. In our model, demyelination or oligodendrocyte apoptosis may be mediated by a direct phagocytic attack of macrophages or also by macrophage derived toxic cytokines. Here, especially TNF- $\alpha$ as a typical NF- $\kappa$ B regulated cytokine in macrophages may play a role [28]. Previous studies already indicated a major role of TNF- $\alpha$ for macrophage recruitment from the periphery [29] and also for oligodendrocyte apoptosis as well as toxic demyelination, especially in the MOG-EAE models of the C57BL/6 mouse [30,31]. Finally, myelin loss might also be influenced by free radicals. As shown, overexpression of NF$\kappa \mathrm{B}$ may lead to an increased expresion of the NF- $\kappa \mathrm{B}$ target gene inducible NO-synthase (iNOS) and thus an increased NO production which was previously shown to exert a detrimental role on oligodendrocytes and in EAE $[32,33]$.

Moreover, reactive oxygen species (ROS) intermediates may induce cellular damage and trigger demyelination as well as a recently shown reversible axonal 


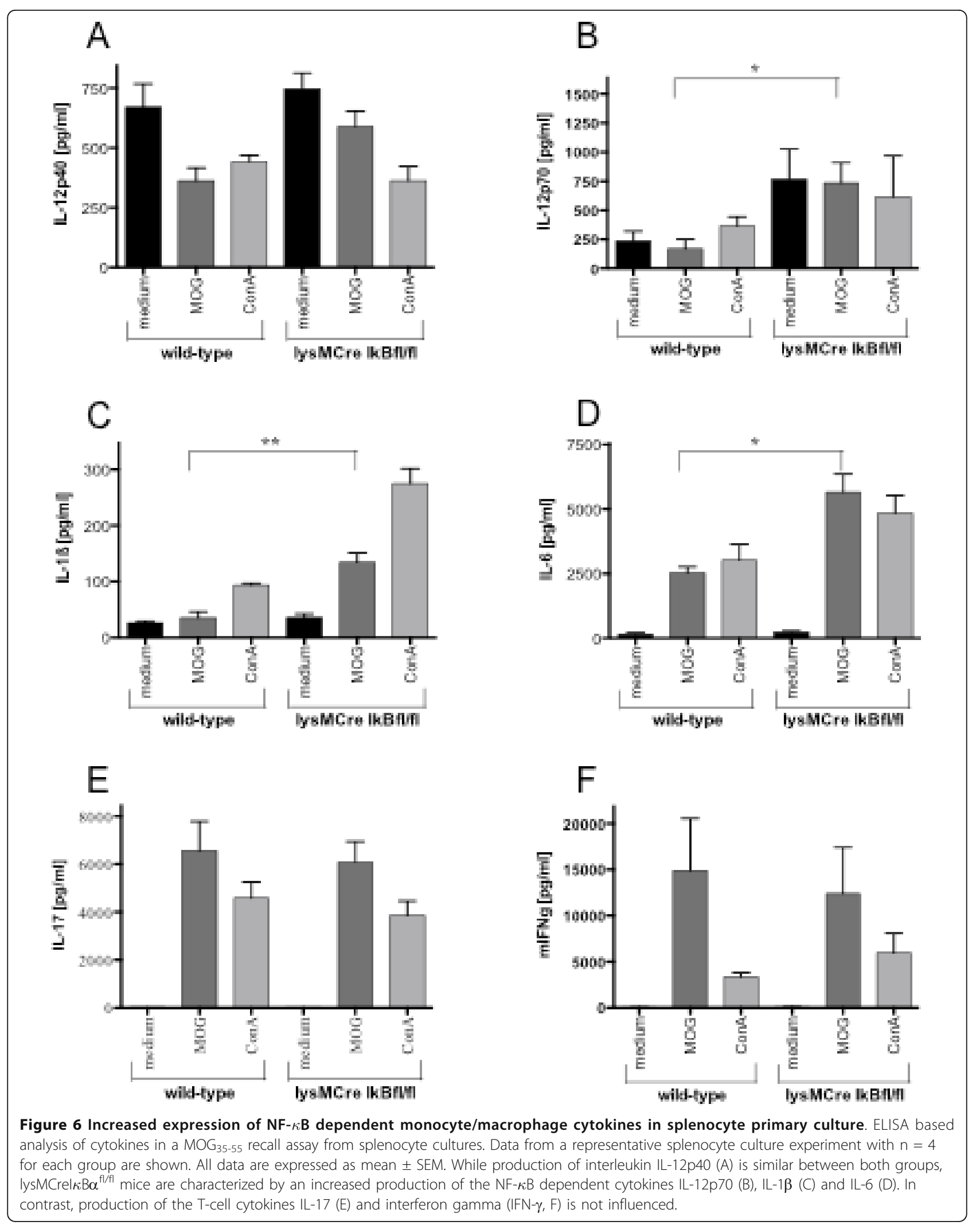


damage called focal axonal degeneration (FAD) [34]. In this process, ROS mediated NF- $\kappa$ B activation [35] and in turn NF- $\kappa \mathrm{B}$ induced further ROS production in macrophages may play an important role. This notion is underscored by the fact that macrophages were found to play an important role in the process of ROS mediated FAD [34].

In our model, further pathways in NF- $\kappa \mathrm{B}$ activation may be involved. Among others, these factors may include toll-like receptors (TLR). In EAE, especially TLR9 on microglia may play an important role for interaction with invading immune cells and for the initiation of a cascade resulting in NF- $\kappa \mathrm{B}$ activation and finally an enhanced innate immune responses [36].

Theoretically, NF- $\kappa \mathrm{B}$ overexpression in macrophages may also exert protective effects in EAE. Indeed, overexpression of the NF- $\kappa \mathrm{B}$ target gene "triggering receptor expressed on myeloid cells 2" (TREM2) in myeloid cells lead to an enhanced expression of anti-inflammatory cytokines in the spinal cord of EAE mice as well as a reduced amount of demyelination and axonal damage [37]. In our setting, overexpression of NF- $\kappa$ B in macrophages predominantly induces destructive effects thus arguing for the prevailing importance of NF- $\kappa \mathrm{B}$ mediated pathways for detrimental phagocyte functions in EAE.

\section{Conclusions}

In summary, our results identify immune-mediated pathways in myeloid cells and in particular monocyte/ macrophage derived NF- $\kappa \mathrm{B}$ as a potential target for therapeutic interventions in the treatment of autoimmune diseases such as MS. This concept is well in line with previous studies using lysMCre mediated conditional gene targeting in macrophages. The myeloid cell specific deletion of the type I interferon receptor also revealed these phagocytes as an interesting therapeutic target in autoimmune neuroinflammation [38].

\section{Acknowledgements}

The skilful technical support of Silvia Seubert is highly appreciated. This work was supported by a grant from the FoRUM programme, Ruhr-University Bochum, Bochum, Germany.

\section{Author details}

${ }^{1}$ Department of Neurology, St. Josef Hospital Bochum, Ruhr-University Bochum, Germany. ${ }^{2}$ Department of Dermatology, Ludwig-MaximilianUniversity Munich, Germany. ${ }^{3}$ Department of Neurology, Friedrich-AlexanderUniversity Erlangen, Germany.

\section{Authors' contributions}

GE carried out the experiments, analyzed histological and immunological results and drafted the manuscript. JT supported cytokine assays and interpretation of results. DHL carried out the confocal laser scanning microscopy. RAR generated the knock-out mice. RG provided general support and participated in the design of the study. RAL conceived the study, and participated in its design and coordination and surveyed and supported the draft of the manuscript. All authors read and approved the final manuscript.

\section{Competing interests}

The authors declare that they have no competing interests.

Received: 14 October 2011 Accepted: 20 January 2012

Published: 20 January 2012

\section{References}

1. Li Q, Verma IM: NF-KB regulation in the immune system. Nature Rev Immunol 2002, 2:725-734.

2. Ghosh S, Karin M: Missing pieces in the NF-KB puzzle. Cell 2002, 109:81-96.

3. Hayden MS, Ghosh S: Signaling to NF-kB. Genes Dev 2004, 18:2195-2224.

4. Li ZW, Rickert RC, Karin M: Genetic dissection of antigen receptor induced NF-kB activation. Mol Immunol 2004, 41:701-714.

5. Pahl H: Activators and target genes of Rel/NF-KB transcription factors. Oncogene 1999, 18:6853-6866.

6. Baeuerle PA, Henkel T: Function and activation of NFKB in the immune system. Annu Rev Immunol 1994, 12:141-179.

7. Grilli M, Jason JS, Leonardo MJ: NF-KB and rel-participants in a multiform transcriptional regulatory system. Int Rev Cytol 1993, 143:1-62.

8. Bours S, Franzoso G, Brown K, Park S, Azarenke V, Tomita YM, Kelly K, Siebenlist U: Lymphocyte activation and the family of NF-KB transcription factor complexes. Curr Top Microbiol Immunol 1992, 182:411-420.

9. Müller JM, Ziegler-Heitbroc JHW, Beauerle PA: Nuclear factor $\kappa B, a$ mediator of lipopolysaccharide effects. Immunbiol 1993, 187:233-256.

10. Geller DA, Nussler AK, Di Silvio RL, Lowenstein CJ, Shapiro RA, Wang SC, Simmons RL, Billiar TR: Cytokines, endotoxin, and glucocorticoids regulate the expression of inducible nitric oxide synthase in hepatocytes. Proc Natl Acad Sci USA 1993, 90:522-526.

11. Yamamoto K, Arakawa T, Ueda N, Yamamoto S: Transcriptional roles of nuclear factor kappa B and nuclear factor-interleukin- 6 in the tumor necrosis factor alpha-dependent induction of cyclooxygenase- 2 in MC3T3-E1 cells. J Biol Chem 1995, 270:31315-31320.

12. Rupec RA, Jundt $F$, Rebholz B, Eckelt $B$, Weindl $G$, Herzinger $T$, Flaig MJ, Moosmann S, Plewig G, Dörken B, Förster I, Huss R, Pfeffer K: Stromamediated dysregulation of myelopoiesis in mice lacking I kappa B alpha. Immunity 2005, 22(4):479-91.

13. Linker RA, Maurer M, Gaupp S, Martini R, Holtmann B, Giess R: CNTF is a major protective factor in demyelinating CND disease: a neurotrophic cytokine as modulator in neuroinflammation. Nat Med 2002, 8:620-624.

14. Mews I, Bergmann M, Bunkowski S, Gullotta F, Brück W: Oligodendrocyte and axon pathology in clinically silent multiple sclerosis lesions. Mult Scler 1998, 4(2):55-62.

15. Kaltschmidt B, Kaltschmidt C: NF-kappaB in the nervous system. Cold Spring Harb Perspect Biol 2009, 1(3):a001271.

16. Tak PP, Firestein GS: NF-kB: a key role in inflammatory diseases. J Clin Invest 2001, 107:7-11.

17. Hilliard BA, Samoilova EB, Liu TS, Rostami A, Chen Y: Experimental autoimmune encephalomyelitis in NF-kB-deficient mice: roles of NF-kB in the activation and differentiation of autoreactive T cells. J Immunol 1999, 163:2937-2943.

18. Hilliard BA, Mason N, Xu L, Sun J, Lamhamedi-Cherradi SE, Liou HC, Hunter C, Chen YH: Critical roles of c-Rel in autoimmune inflammation and helper T cell differentiation. J Clin Invest 2002, 110:843-850.

19. Dasgupta S, Jana M, Zhou Y, Fung YK, Ghosh S, Pahan K: Antineuroinflammatory effect of NF-kappaB essential modifier-binding domain peptides in the adoptive transfer model of experimental allergic encephalomyelitis. J Immunol 2004, 15;173(2):1344-1354.

20. Greve B, Weissert R, Hamdi N, Bettelli E, Sobel RA, Coyle A, Kuchroo VK, Rajewsky K, Schmidt-Supprian M: I kappa B kinase 2/beta deficiency controls expansion of autoreactive $T$ cells and suppresses experimental autoimmune encephalomyelitis. J Immunol 2007, 1;179(1):179-85.

21. Wooten MW: Function for NF-KB in neuronal survival: regulation by atypical protein kinase. C J Neurosci Res 1999, 58:607.

22. Mattson MP, Culmsee $C, Y u Z$, Camandola S: Roles of NF-kB in neuronal survival and plasticity. J Neurochem 2000, 74:443.

23. Martin R, McFarland HF, McFarlin DE: Immunological aspects of demyelinating diseases. Annu Re Immunol 1992, 10:153.

24. Owens $R$, Sriram S: The immunology of MS and of its animal model, EAE. Neurol Clin 1995, 13:51. 
25. Huitinga I, van Rooijen N, de Groot CJA, Uitdehaag BM, Dijkstra CD: Suppression of experimental allergic encephalomyelitis in Lewis rats after elimination of macrophages. J Exp Med 1990, 172:1025-1033.

26. Bauer J, Huitinga I, Zhao W, Lassmann H, Hickey WF, Dijkstra CD: The role of macrophages, perivascular cells, and microglial cells in the pathogenesis of experimental autoimmune encephalomyelitis. Glia 1995, 15(4):437-446

27. Miller SD, MCMahon EJ, Schreiner B, Bailey SL: Antigen presentation in the CNS by myeloid dendritic cells drives progression of relapsing experimental autoimmune encephalomyelitis. Ann N Y Acad Sci 2007, 1103:179-191

28. Collart MA, Baeuerle P, Vassalli P: Regulation of tumor necrosis factor alpha transcription in macrophages: involvement of four kappa B-like motifs and of constitutive and inducible forms of NF-kappa B. Mol Cell Biol 1990, 10(4):1498-1506.

29. Liefner M, Siebert H, Sachse T, Michel U, Kollias G, Brück W: The role of TNF-alpha during Wallerian degeneration. J Neuroimmunol 2000, 108(12):97-103.

30. Probert L, Eugster HP, Akassoglou K, Bauer J, Frei K, Lassmann H, Fontana A: TNFR1 signalling is critical for the development of demyelination and the limitation of T-cell responses during immune-mediated CNS disease. Brain 2000, 123:2005-2019.

31. Louis JC, Magal E, Takayama S, Varon S: CNTF protection of oligodendrocytes against natural and tumor necrosis factor-induced death. Science 1993, 259(5095):689-692.

32. Li S, Vana AC, Ribeiro R, Zhang Y: Distinct role of nitric oxide and peroxynitrite in mediating oligodendrocyte toxicity in culture and in experimental autoimmune encephalomyelitis. Neuroscience 2011, 184:107-119.

33. Okuda Y, Nakatsuji Y, Fujimura H, Esumi H, Ogura T, Yanagihara T, Sakoda S: Expression of the inducible isoform of nitric oxide synthase in the central nervous system of mice correlates with the severity of actively induced experimental allergic encephalomyelitis. J Neuroimmunol 1995, 62(1):103-112.

34. Nikic I, Merkler D, Sorbara C, Birnkoetter M, Kreutzfeldt M, Bareyre FM, Brück W, Bishop D, Misgeld T, Kerschensteiner M: A reversible form of axon damage in experimental autoimmune encephalomyelitis and multiple sclerosis. Nat Med 2011, 17(4):495-499.

35. Schreck R, Meier B, Männel DN, Dröge W, Baeuerle PA: Dithiocarbamates as potent inhibitors of nuclear factor kappa B activation in intact cells. J Exp Med 1992, 175(5):1181-1194.

36. Prinz M, Garbe F, Schmidt H, Mildner A, Gutcher I, Wolter K, Piesche M, Schroers R, Weiss E, Kirschning CJ, Rochford CD, Brück W, Becher B: Innate immunity mediated by TLR9 modulates pathogenicity in an animal model of multiple sclerosis. J Clin Invest 2006, 116(2):456-64.

37. Takahashi K, Prinz M, Stagi M, Chechneva O, Neumann H: TREM2transduced myeloid precursors mediate nervous tissue debris clearance and facilitate recovery in an animal model of multiple sclerosis. PLOS Med 2007, 4(4):675-689.

38. Prinz M, Schmidt H, Mildner A, Knobeloch KP, Hanisch UK, Raasch J, Merkler D, Detje C, Gutcher I, Mages J, Lang R, Martin R, Gold R, Becher B, Brück W, Kalinke U: Distinct and nonredundant in vivo functions of IFNAR on myeloid cells limit autoimmunity in the central nervous system. Immunity 2008, 28:675-686.

doi:10.1186/1742-2094-9-15

Cite this article as: Ellrichmann et al:: Constitutive activity of NF-kappa B in myeloid cells drives pathogenicity of monocytes and macrophages during autoimmune neuroinflammation. Journal of Neuroinflammation 2012 9:15.

\section{Submit your next manuscript to BioMed Central and take full advantage of:}

- Convenient online submission

- Thorough peer review

- No space constraints or color figure charges

- Immediate publication on acceptance

- Inclusion in PubMed, CAS, Scopus and Google Scholar

- Research which is freely available for redistribution

Submit your manuscript at www.biomedcentral.com/submit
Biomed Central 